\title{
Epidemiology, prevention, and treatment of new-onset atrial fibrillation in critically ill: a systematic review
}

\author{
Takuo Yoshida, Tomoko Fujii, Shigehiko Uchino ${ }^{*}$ and Masanori Takinami
}

\begin{abstract}
Background: Atrial fibrillation (AF) is a common arrhythmia in the ICU. The aim of this review is to summarize relevant information on new-onset AF in non-cardiac critical illness with respect to epidemiology, prevention, and treatment.

Methods: We conducted a PubMed search in June 2014 and included studies describing the epidemiology, prevention, and treatment of new-onset AF and atrial flutter during ICU stay in non-cardiac adult patients. Selected studies were divided into the three categories according to the extracted information. The methodological quality of selected studies was described according to the Grading of Recommendations Assessment, Development and Evaluation system.

Results: We identified 1,132 citations, and after full-text-level selection, we included 10 studies on etiology/outcome and five studies on treatment. There was no study related to prevention. Overall quality of evidence was mostly low or very low due to their observational study designs, small sample sizes, flawed diagnosis of new-onset AF, and the absence of mortality evaluation. The incidence of new-onset AF varied from $4.5 \%$ to $15.0 \%$, excluding exceptional cases (e.g., septic shock). Severity scores of patients with new-onset AF were higher than those without new-onset AF in eight studies, in four of which the difference was statistically significant. Five studies reported risk factors for new-onset AF, all of which used multivariate analyses to extract risk factors. Multiple risk factors are reported, e.g., advanced age, the white race, severity scores, organ failures, and sepsis. Hospital mortality in new-onset AF patients was higher than that of patients without AF in all studies, four of which found statistical significance. Among the five studies on treatment, only one study was randomized controlled, and various interventions were studied.

Conclusions: New-onset AF occurred in 5\%-15\% of the non-cardiac critically ill patients. Patients with new-onset AF had poor outcomes compared with those without AF. Despite the high incidence of new-onset AF in the general ICU population, currently available information for AF, especially for management (prevention, treatment, and anticoagulation), is quite limited. Further research is needed to improve our understanding of new-onset AF in critically ill patients.
\end{abstract}

Keywords: Atrial fibrillation, Critical care, Outcome, Prevention, Treatment, Systematic review

\footnotetext{
*Correspondence: s.uchino@mac.com

Intensive Care Unit, Department of Anesthesiology, The Jikei University

School of Medicine, 3-19-18, Nishi-Shinbashi, Minato-ku, Tokyo 105-8471,

Japan
} 


\section{Background}

Atrial fibrillation (AF) is a common arrhythmia in critically ill patients [1-4]. To date, multiple studies on incidence, prophylaxis, and treatment of new-onset AF in specific cohorts have been published, such as cardiac surgery [5-15], non-cardiac surgery [16-23], and medical diseases [24-27]. Especially in cardiac surgery and cardiac diseases, incidence and treatment of AF have been extensively investigated, which have led to publication of many reviews and established recommendations in guidelines [28-35]. Compared with the amount of knowledge for cardiac diseases, however, information on AF occurring in general critically ill populations is limited [36,37].

Another issue related to AF in critically ill patients is their ambiguous inclusion criteria of the study population, in which supraventricular arrhythmia (SVA) or atrial tachycardia was often grouped with $\mathrm{AF}$ and atrial flutter $[1,16,19,24]$. AF and atrial flutter are different from SVA or atrial tachycardia in pathophysiology that lies behind them and treatment goals [38-40]. The goal of treatment for $\mathrm{AF}$ and atrial flutter might be rhythm conversion to improve cardiac output and preventing thromboembolic events [32-34,41-47]. However, a lack of information concentrating on $\mathrm{AF}$ and atrial flutter makes it difficult to decide whether clinicians should do any interventions for the arrhythmia.

The aim of this review is to summarize relevant information concentrating on new-onset $\mathrm{AF}$ in non-cardiac critically ill patients with respect to epidemiology, prevention, and treatment.

\section{Methods}

\section{Data sources and searches}

We conducted a PubMed search in June 2014 using the following $\mathrm{MeSH}$ and keyword terms: "atrial fibrillation" or "atrial flutter" or "(atrial or supraventricular) and (tachycardia or tachyarrhythmia or arrhythmia)" and "intensive care" or "critical care" or "critically ill" or "critical illness." Only articles published in English were considered for this systematic review.

\section{Study selection}

The primary author (TY) and the secondary author (TF) independently screened titles and abstracts of articles identified by the search and checked in full-text level for concise selection. We included studies describing the epidemiology, prevention, and treatment of new-onset $\mathrm{AF}$ and atrial flutter during ICU stay in non-cardiac adult patients. Exclusion criteria were studies without description of settings as ICU, studies that focused exclusively on a perioperative period of a specific procedure, studies mainly on patients with heart diseases and cardiac surgery, and studies that did not exclude patients with past history of AF. We also excluded reviews and commentaries that did not contain original information and reports that were published only in abstract form and that provided no clear definition of patients or arrhythmias studied. Reports on patients with severe sepsis and septic shock but that were not specifically mentioned to be conducted in the ICU were included because those patients were highly expected to have been in the ICU. While atrial flutter was included because of its risk of thromboembolic events similar to AF, SVA, which was not specified further, was excluded in this review as it was out of our scope as mentioned above. Disagreement was adjudicated through consensus of the two reviewers.

As this study of a systematic review did not contain human research, approval of an institutional review board was waived.

\section{Data extraction and quality assessment}

The primary author (TY) extracted information for the systematic review and undertook quality assessment. Selected studies were divided into three categories according to the extracted information: etiology/outcome, prevention, and treatment. The methodological quality of selected studies was described according to the Grading of Recommendations Assessment, Development and Evaluation (GRADE) system [48]. Extracted data to evaluate the risk of bias, indirectness, and imprecision were as follows: details of diagnosis of AF, allocation concealment, blinding, detailed description of conversion from AF to sinus rhythm, applicability of each study population, reported outcome, and sample sizes. We scored all items and classified into four categories from very low to high as overall quality.

\section{Results}

Figure 1 shows the flow chart of studies selected in the systematic review. We identified 1,132 citations and 66 studies were evaluated in full-text review. Thirty-two of the 66 studies related to etiology/outcome, nine studies related to prevention, and 26 studies related to treatment. After full-text-level selection, we included in this review ten studies on etiology/outcome [26,49-57] and five studies on treatment $[51,53,55,58,59]$. On the other hand, there was no study related to prevention that could be included in this review. Although there were two studies on prevention performed in the ICU, they focused on patients after lung resection surgery and thus were excluded $[60,61]$. Three studies were related to both etiology/outcome and treatment $[51,53,55]$. In the study by Balser et al., they screened SVA and included only those who did not convert to sinus rhythm after an adenosine challenge to rule out reentrant atrioventricular nodal rhythm and ventricular tachyarrhythmia, so that this study was included in this review [58]. 


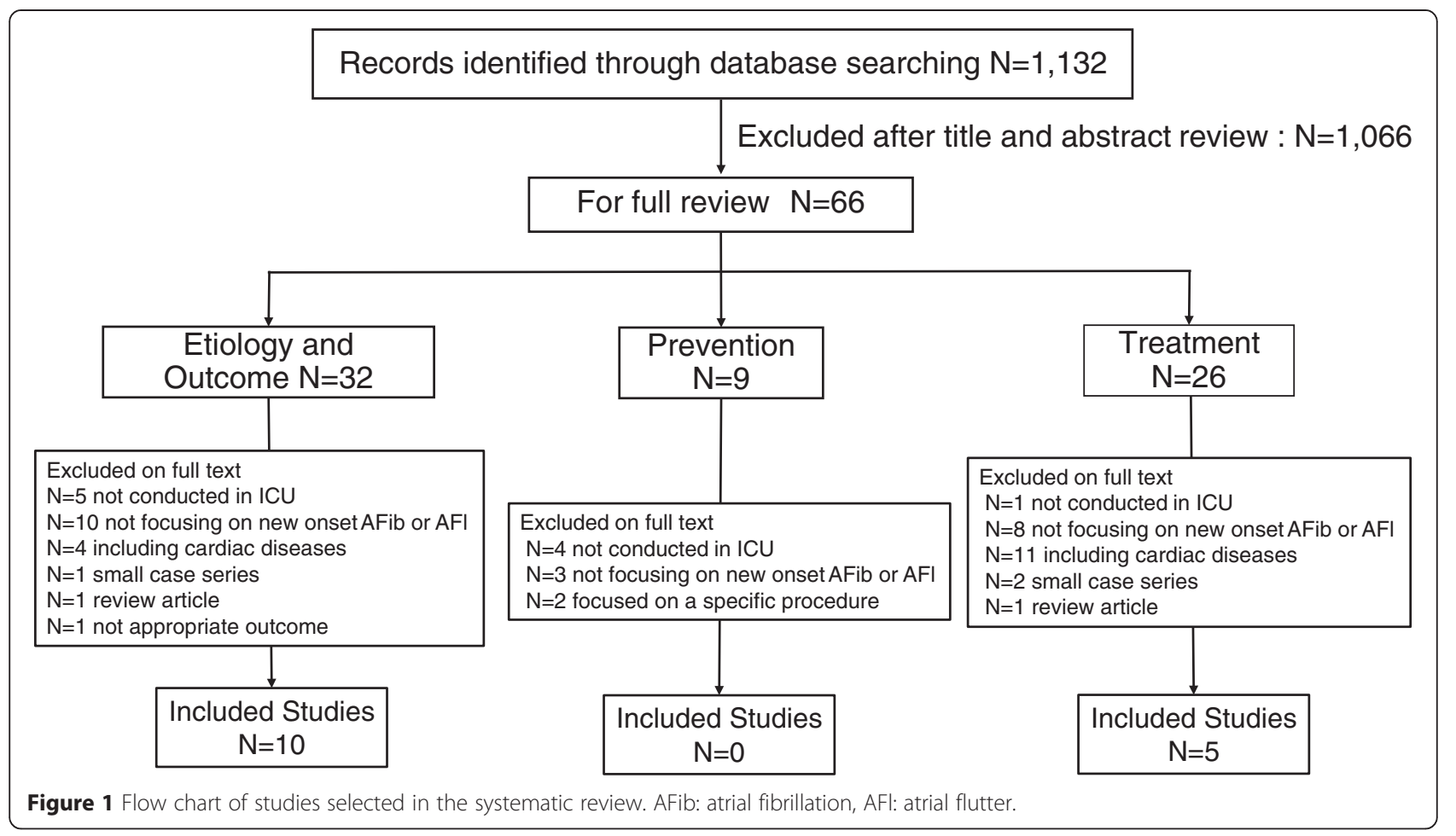

Table 1 shows the overall characteristics of included studies. Of the ten studies for etiology/outcome, three studies were retrospective studies and the others were prospective. Of the five studies for treatment, there was only one randomized controlled trial (RCT). The number of patients included in each study varied from 29 to 49,082. Although one study was not performed in the ICU, it met our criteria as it was of septic shock patients [54].

Table 2 shows the methodological quality of included studies. Overall quality of evidence was low or very low due to their observational study designs, small sample sizes, flawed diagnosis of new-onset AF, and the absence of mortality evaluation.

Table 3 shows incidences of AF and severity scores of the study population. In four studies performed in the surgical ICU, the incidence of new-onset AF was similar, ranging from $5.3 \%$ to $7.8 \%$ [49-51,54]. The incidence varied from $4.5 \%$ to $29.5 \%$ in four studies performed in the mixed ICU $[26,52,55,57]$. In a single study performed in the medical ICU, the incidence of AF was 13.8\% [56].

Table 1 Overall characteristics of included studies

\begin{tabular}{lllll}
\hline Author, year [ref] & Study design & No. of patients & Setting (patients) & Outcome \\
\hline Bender JS, 1996 [49] & Prospective observational & 206 & Surgical ICU & Etiology \\
Seguin P, 2004 [50] & Prospective observational & 453 & Surgical ICU & Etiology/outcome \\
Seguin P, 2006 [51] & Prospective observational & 293 & Surgical ICU (trauma) & Etiology/outcome treatment \\
Arora S, 2007 [52] & Prospective observational & 61 & Mixed ICU & Etiology/outcome \\
Christian SA, 2008 [26] & Retrospective observational & 272 & Mixed ICU (sepsis) & Etiology/outcome \\
Meierhenrich R, 2010 [53] & Prospective observational & 629 (50 septic shock) & Surgical ICU & Etiology/outcome treatment \\
Walkey AJ, 2011 [54] & Retrospective population-based cohort & 49,082 & Acute care hospitals & Etiology/outcome \\
Kanji S, 2012 [55] & Retrospective observational & 3,081 & (severe sepsis) & Etiology treatment \\
Tongyaoo S, 2013 [56] & Prospective observational & 247 & Three mixed ICUs & Etiology/outcome \\
Makrygiannis SS, 2014 [57] & Prospective observational & 133 & Medical ICU & Etiology \\
Balser JR, 1998 [60] & Randomized controlled & $64^{\mathrm{a}}$ & Mixed ICU & Treatment \\
Sleeswijk ME, 2008 [61] & Prospective observational & 29 & Mixed ICU & Treatment \\
\hline
\end{tabular}

${ }^{\mathrm{a}}$ Number of patients with supraventricular tachyarrhythmia (not focusing on AFib and AFI). 


\section{Table 2 Methodological quality of included studies}

\begin{tabular}{|c|c|c|c|c|c|c|}
\hline Author, year [ref] & Main outcome & Study design & Risk of bias & Indirectness & Imprecision $^{a}$ & Overall quality \\
\hline Bender JS, 1996 [49] & Etiology/outcome & Prospective (0.5), observational (2) & AF diagnosis unclear $(-1)$ & Mortality not evaluated $(-0.5)$ & & Very low (1) \\
\hline Seguin P, 2004 [50] & Etiology/outcome & Prospective (0.5), observational (2) & & & & Low (2.5) \\
\hline Seguin P, 2006 [51] & Etiology/outcome & Prospective (0.5), observational (2) & & Only trauma patients $(-0.5)$ & & Low (2) \\
\hline Seguin P, 2006 [51] & Treatment & Prospective (0.5), observational (2) & & $\begin{array}{l}\text { Absence of definition for } \\
\text { conversion time }(-1)\end{array}$ & $N=16(-1)$ & Very low (0.5) \\
\hline Arora S, 2007 [52] & Etiology/outcome & Prospective (0.5), observational (2) & & & $N=61(-1)$ & Very low (1.5) \\
\hline Christian SA, 2008 [26] & Etiology/outcome & Observational (2) & $\begin{array}{l}\text { Retrospective diagnosis of AF } \\
(-1)\end{array}$ & Only septic patients $(-0.5)$ & & Very low $(0.5)$ \\
\hline Meierhenrich R, 2010 [53] & Etiology/outcome & Prospective (0.5), observational (2) & & & & Low (2.5) \\
\hline Meierhenrich R, 2010 [53] & Treatment & Prospective (0.5), observational (2) & & $\begin{array}{l}\text { Unknown efficacy of each } \\
\text { treatment }(-1)\end{array}$ & $N=49(-1)$ & Very low (0.5) \\
\hline Walkey AJ, 2011 [54] & Etiology/outcome & Observational (2) & $\begin{array}{l}\text { Retrospective diagnosis of AF } \\
(-1)\end{array}$ & Only septic patients $(-0.5)$ & $N=49,082(+2)$ & $\operatorname{Low}(2.5)$ \\
\hline Kanji S, 2012 [55] & Etiology/outcome & Observational (2) & $\begin{array}{l}\text { Retrospective diagnosis of AF } \\
(-1)\end{array}$ & & $N=2,895(+1)$ & Low (3) \\
\hline Kanji S, 2012 [55] & Treatment & Observational (2) & $\begin{array}{l}\text { Retrospective diagnosis of AF } \\
(-1)\end{array}$ & $\begin{array}{l}\text { Unknown efficacy of each } \\
\text { treatment }(-1)\end{array}$ & & Very low (0) \\
\hline Tongyaoo S, 2013 [56] & Etiology/outcome & Prospective (0.5), observational (2) & & & & $\operatorname{Low}(2.5)$ \\
\hline Makrygiannis SS, 2014 [57] & Etiology/outcome & Prospective (0.5), observational (2) & & Mortality not evaluated $(-0.5)$ & & Low (2) \\
\hline Balser JR, 1998 [60] & Treatment & Randomized (4) & $\begin{array}{l}\text { Open label }(-0.5) \text {, Allocation } \\
\text { concealment unclear }(-0.5)\end{array}$ & Mortality not evaluated $(-0.5)$ & $N=64(-1)$ & Very low (1.5) \\
\hline Sleeswijk ME, 2008 [61] & Treatment & Prospective (0.5), observational (2) & & Mortality not evaluated $(-0.5)$ & $N=29(-1)$ & Very low (1) \\
\hline
\end{tabular}


Table 3 Incidences of new-onset atrial fibrillation and severity scores of the study population

\begin{tabular}{|c|c|c|c|c|}
\hline Author, year [ref] & Setting patients & Incidence of AF (no.) & Severity score & Mean score $^{a}$ \\
\hline Bender JS, 1996 [49] & Surgical ICU & $6.8 \%(14 / 206)$ & NA & NA \\
\hline Seguin P, 2004 [50] & Surgical ICU & $5.3 \%(24 / 453)$ & SAPS $\|$ & 45 vs. $31(p=0.0001)$ \\
\hline Seguin P, 2006 [51] & Surgical ICU (trauma) & $5.5 \%(16 / 293)$ & SAPS $\|$ & 47 vs. $31(p<0.001)$ \\
\hline \multirow[t]{2}{*}{ Arora S, 2007 [52] } & \multirow[t]{2}{*}{ Mixed ICU } & \multirow[t]{2}{*}{$29.5 \%(18 / 61)$} & APACHE ॥ & 25.4 vs. $20.0(p=0.005)$ \\
\hline & & & SAPS $\|$ & 47.8 vs. $37.1(p=0.001)$ \\
\hline Christian SA, 2008 [26] & Mixed ICU (sepsis) & $5.9 \%(16 / 272)$ & APACHE II predicted survival & $49 \%$ vs. $55 \%(p=0.36)$ \\
\hline \multirow[t]{2}{*}{ Meierhenrich R, 2010 [53] } & \multirow[t]{2}{*}{ Surgical ICU } & All patients 7.8\% (49/629) & \multirow[t]{2}{*}{ SAPS $\|$} & NA \\
\hline & & Septic shock $46.0 \%(23 / 50)$ & & 31 vs. $30^{\mathrm{b}}(p=0.12)$ \\
\hline Walkey AJ, 2011 [54] & Acute care hospitals (severe sepsis) & $5.9 \%(2,896 / 49,082)$ & Number of organ failures & 3.11 vs. $3.08^{\mathrm{b}}(p=0.42)$ \\
\hline Kanji S, 2012 [55] & Three mixed ICUs & $4.5 \%(139 / 3,081)$ & APACHE ॥ & $22.6^{c}$ \\
\hline Tongyaoo S, 2013 [56] & Medical ICU & $13.8 \%(34 / 247)$ & APACHE ॥ & 24.4 vs. $17.0^{d}(p<0.001)$ \\
\hline Makrygiannis SS, 2014 [57] & Mixed ICU & $15.0 \%(20 / 133)$ & APACHE ॥ & 17.9 vs. $15.7(p=0.16)$ \\
\hline
\end{tabular}

AF atrial fibrillation, APACHE II Acute Physiology and Chronic Health Evaluation II, SAPS II Simplified Acute Physiology Score II, NA not available.

${ }^{a}$ Atrial fibrillation vs. no atrial fibrillation.

${ }^{\mathrm{b}}$ Median.

${ }^{\mathrm{C}}$ No information for APACHE II in no new-onset AF patients provided.

${ }^{d}$ All types of supraventricular tachyarrhythmia included.

When focused on sepsis and severe sepsis, new-onset AF occurred in $5.9 \%$ of septic patients [26,54], which was similar to that in surgical ICU populations. However, the incidence jumped up to $46.0 \%$ in patients with septic shock [53]. Most studies reported a severity of illness with Simplified Acute Physiology Score (SAPS) II [62] or Acute Physiology and Chronic Health Evaluation (APACHE) II score [63]. Severity scores of patients with new-onset AF were reported to be higher than those without new-onset AF in eight studies, in four of which the difference was statistically significant [50-52,56].

Table 4 shows a list of risk factors for new-onset AF. Five studies reported risk factors for new-onset AF, all of which used multivariate analyses to extract risk factors [50-52,55,58]. All studies reported advanced age in common, two studies reported right heart catheter [50,55], and two studies reported sepsis [52,58] as independent risk factors. Medication with $\beta$-blocking agents was shown not to have any relationship with new-onset AF in three studies [50-52]. In turn, one study reported that medication with calcium channel blockers had a positive relationship with the incidence of new-onset AF [50]. Severity of illness was evaluated in four studies, three of which found severity of illness (SAPS II $\geq 30$, shock, three or more regions traumatized, SIRS, APACHE II score $\geq 20$ ) to have high odds ratios for new-onset AF with statistical significance.

Table 5 and Figure 2 show outcomes of new-onset AF. Among eight studies reporting outcomes of AF patients, new-onset AF was associated with increased ICU length of stay in four studies $[26,50,51,53]$ and increased hospital length of stay in one study [50]. Three studies reported the incidence of stroke that ranged from $0 \%$ to
5.9\% [54-56]. A large cohort study of severe sepsis showed a significantly higher incidence of stroke in the new-onset AF group compared with the non-AF group ( $2.6 \%$ vs. $0.7 \%, p<0.0001)$ [54]. Only one study referred to systemic therapeutic anticoagulation, in which $16 \%$ of the patients with new-onset AF were treated [55]. None of the study patients with new-onset AF had a stroke during the course of AF. Hospital mortality rates in new-onset AF groups were higher than those of no-AF groups in seven studies, in which four studies found statistical significance (Figure 2) [26,50,52,54]. However, none of the studies evaluated the impact of new-onset AF on mortality with multivariate analysis including severity scores.

Table 6 shows the efficacy of treatment for new-onset AF. There were five studies on treatment for new-onset AF $[51,53,55,58,59]$. Balser et al., the only RCT among the five studies, evaluated a conversion rate from AF to sinus rhythm within $2 \mathrm{~h}$ after starting administration of either esmolol or diltiazem [58]. There was no statistical difference in the conversion rate between the two study drugs $(59.1 \%$ vs. $27.3 \%, p=0.067)$. Kanji et al. reported a conversion rate within $24 \mathrm{~h}$ after various interventions. They did not describe details of combination of rhythm control therapies (direct current cardioversion, amiodarone, sotalol) and rate control therapies ( $\beta$-blockers, calcium channel blockers, or digoxin, alone or in combination), so that the conversion rate could not be directly comparable to each intervention [55]. Sleeswijk et al. evaluated an efficacy of a protocol of magnesium sulfate $\left(\mathrm{MgSO}_{4}\right)$-amiodarone step-up scheme, which was $\mathrm{MgSO}_{4}$ administration followed by additional administration of amiodarone if no conversion to sinus rhythm 
Table 4 Risk factors for new-onset atrial fibrillation

\begin{tabular}{|c|c|c|c|}
\hline Category & Risk factor & OR $(95 \% \mathrm{Cl})$ & Reference \\
\hline \multirow[t]{8}{*}{ Demographics } & Age $>65$ years & $7.0(2.0-24.6)$ & {$[58]$} \\
\hline & Age $\geq 40$ years & $6.3(1.4-28.7)$ & [51] \\
\hline & Age $\geq 75$ years & $4.79(1.16-19.8)$ & {$[52]$} \\
\hline & Age, per 10 years & $1.52(1.47-1.56)$ & {$[54]$} \\
\hline & Advanced age & $1.04(1.01-1.07)$ & {$[50]$} \\
\hline & Female sex & $0.83(0.76-0.90)$ & {$[54]$} \\
\hline & $\begin{array}{l}\text { Hispanic } \\
\text { (white as reference) }\end{array}$ & $0.58(0.50-0.63)$ & {$[54]$} \\
\hline & Black (white as reference) & $0.67(0.58-0.78)$ & {$[54]$} \\
\hline \multirow[t]{6}{*}{ Past history } & Calcium channel blockers & $3.87(1.18-12.7)$ & {$[50]$} \\
\hline & Prior stroke & $1.64(1.35-2.01)$ & [54] \\
\hline & $\begin{array}{l}\text { Metastatic/hematologic } \\
\text { malignancy }\end{array}$ & $1.23(1.09-1.39)$ & {$[54]$} \\
\hline & Obesity & $1.20(1.03-1.40)$ & {$[54]$} \\
\hline & Hypertension & $0.88(0.81-0.95)$ & {$[54]$} \\
\hline & Diabetes mellitus & $0.82(0.75-0.90)$ & {$[54]$} \\
\hline \multirow[t]{4}{*}{ Severity } & SAPS $\| \geq 30$ & $11.6(1.3-103.0)$ & {$[51]$} \\
\hline & Shock & $6.77(2.17-21.1)$ & {$[50]$} \\
\hline & SIRS & $4.4(1.2-16.1)$ & [51] \\
\hline & APACHE II score $\geq 20$ & $3.90(1.00-16.7)$ & {$[52]$} \\
\hline \multirow[t]{6}{*}{ Organ failure } & Respiratory failure & $2.81(2.48-3.19)$ & {$[54]$} \\
\hline & Congestive heart failure & $1.61(1.41-1.83)$ & {$[54]$} \\
\hline & Hematologic failure & $1.50(1.34-1.68)$ & {$[54]$} \\
\hline & Renal failure & $1.40(1.26-1.56)$ & {$[54]$} \\
\hline & Per organ failure & $1.12(1.05-1.19)$ & {$[54]$} \\
\hline & Acidosis & $0.87(0.77-0.97)$ & {$[54]$} \\
\hline \multirow[t]{2}{*}{ Trauma } & Blunt thoracic trauma & $16.8(4.00-71.2)$ & {$[50]$} \\
\hline & $\begin{array}{l}\text { Three or more regions } \\
\text { traumatized }\end{array}$ & $6.2(1.8-21.4)$ & [51] \\
\hline \multirow[t]{9}{*}{ Infection } & Sepsis & $6.5(2.0-21.1)$ & {$[57]$} \\
\hline & Sepsis at admission & $4.87(1.24-18.8)$ & {$[52]$} \\
\hline & Abdominal infection & $1.77(1.59-1.97)$ & {$[54]$} \\
\hline & Fungal infection & $1.59(1.27-2.00)$ & {$[54]$} \\
\hline & Respiratory tract infection & $1.27(1.14-1.40)$ & {$[54]$} \\
\hline & $\begin{array}{l}\text { Skin or soft tissue } \\
\text { infection }\end{array}$ & $1.33(1.14-1.55)$ & [54] \\
\hline & Gram-positive bacteria & $1.29(1.18-1.55)$ & {$[54]$} \\
\hline & Primary bacteremia & $1.17(1.02-1.36)$ & {$[54]$} \\
\hline & Urinary tract infection & $0.89(0.81-0.99)$ & {$[54]$} \\
\hline \multirow[t]{3}{*}{ Intervention } & Catecholamine use & $5.7(1.7-19.1)$ & [51] \\
\hline & Pulmonary artery catheter & $5.46(1.84-16.2)$ & {$[50]$} \\
\hline & Right heart catheterization & $2.25(1.87-2.70)$ & [54] \\
\hline
\end{tabular}

OR odds ratio, APACHE II Acute Physiology and Chronic Health Evaluation II, Cl confidence interval, SAPS II Simplified Acute Physiology Score II, SIRS systemic inflammatory response syndrome. or no reduction of the ventricular rate under 110 beats/ min was attained. Although this study was not a comparative study, the reported conversion rate was high (93.1\%) [59]. Meierhenrich et al. reported $85.7 \%$ of a conversion rate with various interventions, including direct current cardioversion, amiodarone, digitalis glycosides, and $\beta$ blockers, alone or in combination [53]. ICU mortality was significantly higher in patients who failed to be cardioverted than those who were converted $(71.4 \%$ vs. $21.4 \%, p=0.015)$.

\section{Discussion}

In this systematic review, we found that the incidence of new-onset AF in non-cardiac critically ill patients widely ranged. Meierhenrich et al. reported a high rate of AF among septic shock patients (46.0\%) [53]. Arora et al. reported an incidence of $29.5 \%$ in their mixed ICU, where more than $95 \%$ of patients were mechanically ventilated and nearly 30\% received renal replacement therapy [52]. Excluding these two studies with exceptionally severe cases, the incidence of new-onset AF for non-cardiac critically ill patients in the general ICU was from $4.5 \%$ to $15.0 \%$. Postoperative AF had been reported to occur in $15 \%$ to $50 \%$ of patients with cardiac surgery [32,33] and $10 \%$ to $42 \%$ with thoracic surgery [18-24], suggesting that these two specific cohorts might have a higher incidence of AF compared with the general ICU population. Since the risk factor with the highest odds ratio for new-onset $\mathrm{AF}$ was blunt thoracic trauma (Table 4 , odds ratio $=16.8$ ), a directly invasive procedure or trauma on the thorax might significantly contribute to the occurrence of new-onset AF in critically ill patients. Nonetheless, the incidence range in our review (5\% to $15.0 \%$ ) is higher than previously thought (4\% to $9 \%$ ) [3], possibly due to the aging population and development of more complex surgical procedures.

Severity of illness (APACHE II, SAPS II, SIRS, shock), organ failures, and sepsis were all reported as risk factors of AF in multiple studies. A subgroup of septic shock patients also had a markedly high incidence of new-onset AF (46\%) [53]. These findings suggest that systematic inflammation might have a role in triggering AF in critically ill patients. Studies in cardiac surgery and the general population also reported that systemic inflammation could trigger $\mathrm{AF}$, and there have been clinical trials using anti-inflammatory agents, such as colchicine and corticosteroid, to prevent or treat AF [10,12-15,64]. The effect of anti-inflammatory agents for AF in critically ill patients is unknown and further studies are needed. In the well-known CORTICUS study (hydrocortisone therapy for patients with septic shock), the incidence of AF or any types of arrhythmias was unfortunately not reported [65].

Although studies in cardiac surgery patients showed that $\beta$-blockers had a prophylactic effect for postoperative AF [29-35], none of the studies in this review showed a 
Table 5 Outcomes of patients with new-onset atrial fibrillation

\begin{tabular}{|c|c|c|c|}
\hline Author, year [ref] & ICU LOS (days, mean) & Hospital LOS (days, mean) & Stroke $(\%)$ \\
\hline Seguin P, 2004 [50] & 16 vs. $7(p=0.0001)$ & 34 vs. $22(p=0.009)$ & NA \\
\hline Seguin P, 2006 [51] & 22 vs. $10(p<0.001)$ & 32 vs. $25(p=0.259)$ & NA \\
\hline Arora S, 2007 [52] & 10 vs. $4^{\mathrm{a}}$ (NS) & 47 vs. $22^{a}$ (NS) & NA \\
\hline Christian SA, 2008 [26] & 17.7 vs. $8.3(p=0.003)$ & 32.1 vs. $28.5(p=0.68)$ & NA \\
\hline Meierhenrich R, 2010 [53] & 30 vs. $17^{\mathrm{ab}}(p=0.017)$ & NA & NA \\
\hline Walkey AJ, 2011 [54] & NA & NA & 2.6 vs. $0.7(p<0.0001)$ \\
\hline Kanji S, 2012 [55] & $10^{\mathrm{ac}}$ & $24^{\mathrm{ac}}$ & 0 \\
\hline Tongyaoo S, 2013 [56] & NA & NA & 5.9 vs. $2.0^{d}$ \\
\hline
\end{tabular}

Atrial fibrillation vs. no atrial fibrillation.

$A F$ atrial fibrillation, LOS length of stay, NA not available, NS not significant.

${ }^{a}$ Median.

${ }^{b}$ Data focusing on septic shock patients.

'Data with new-onset AF alone.

${ }^{d} p$ value not provided.

significant relationship between $\beta$-blockers and occurrence of new-onset AF. On the other hand, previous treatment with calcium channel blockers was reported as a risk factor of new-onset AF in one study, in which $70 \%$ of the patients received calcium channel blockers for hypertension [50]. Although hypertension was a major risk factor for AF in general populations, the authors of the study did not take a past history of hypertension into consideration in their analysis. As the authors discussed in their article, the association between previous medication with calcium channel blockers and new-onset AF was not conclusive. Walkey et al. reported a negative association between a previous history of hypertension and new-onset AF among septic patients (odds ratio $=0.88$ ) [54]. As this study was a retrospective observational study using disease classification codes in in-patient databases, there might have been a reporting bias (e.g., less frequent coding of chronic comorbidities). To solve this uncertainty, future studies for risk factors of AF in the critically ill should include both a past history of hypertension and previous antihypertensive treatment, especially $\beta$-blockers and calcium channel blockers.

Walkey et al. presented increased risks of stroke associated with new-onset AF in septic shock patients [54]. In a recent prospective observational study on SVA, CHADS2 and CHA2DS2-VASc predicted SVA-related arterial thromboembolic events in critically ill patients, and the most accurate threshold was a CHADS2 score of 4 or higher [66]. On the other hand, Kanji S et al. reported that only $16 \%$ of new-onset AF patients in their study were given systemic anticoagulation and the incidence of stroke was $0 \%$ during the course of AF [55]. They also reported that $9 \%$ of patients with systemic anticoagulation had a bleeding event that required blood transfusion. Although ACC/AHA/ESC practice guidelines recommended anticoagulation for new-onset AF of more than $48 \mathrm{~h}$ of duration in the general population [33], it is currently unclear whether non-cardiac critically ill patients with new-onset AF should be anticoagulated to prevent arterial thromboembolic events. Intensive

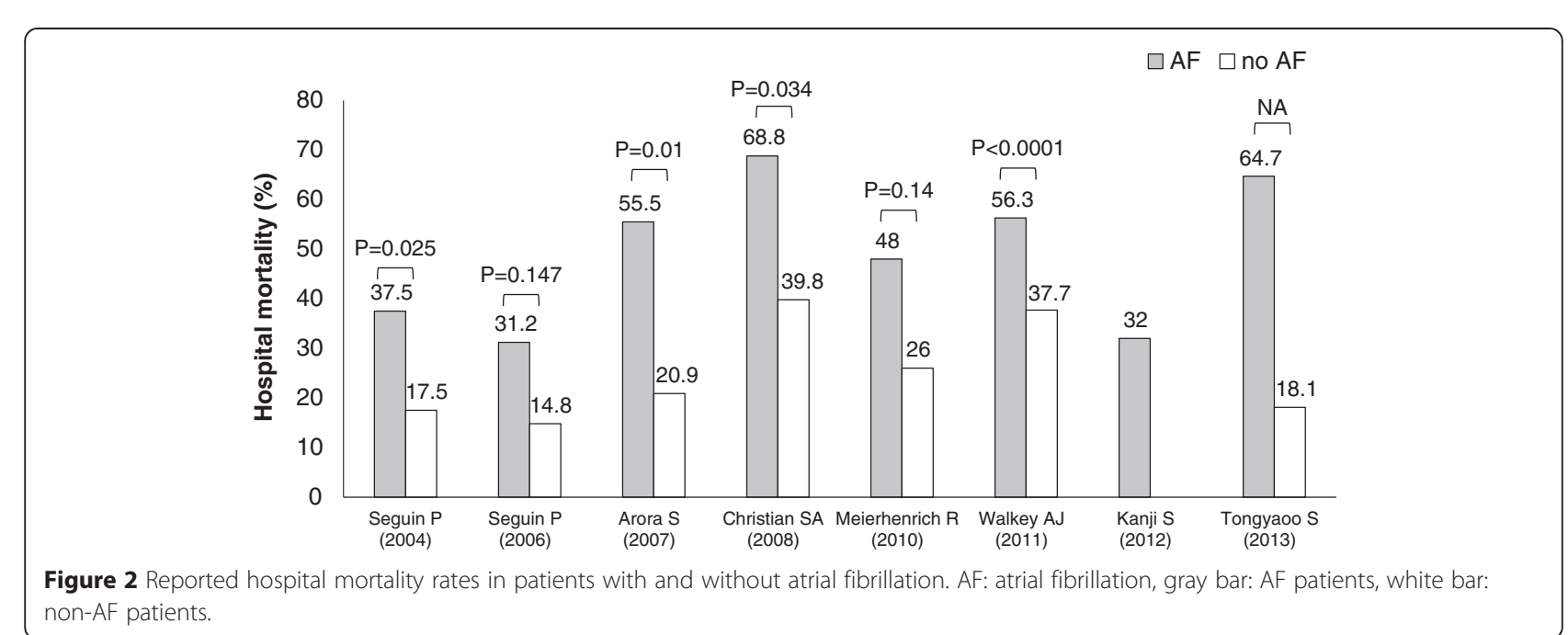


Table 6 Efficacy of treatment for new-onset atrial fibrillation

\begin{tabular}{|c|c|c|c|c|c|c|c|c|}
\hline \multirow{2}{*}{$\begin{array}{l}\text { Author, year [ref] } \\
\text { Balser JR, } 1998 \text { [58] }\end{array}$} & \multirow{2}{*}{$\begin{array}{l}\text { Study design } \\
\text { Randomized controlled }\end{array}$} & \multicolumn{2}{|c|}{ Severity score } & \multirow{2}{*}{$\begin{array}{l}\text { Observation period } \\
\text { Within } 2 \mathrm{~h}\end{array}$} & \multirow{2}{*}{$\begin{array}{l}\text { Intervention } \\
\text { Esmolol }\end{array}$} & \multicolumn{2}{|l|}{ Conversion rate } & \multirow{2}{*}{$\begin{array}{l}\text { Hospital mortality (\% } \\
31\end{array}$} \\
\hline & & APACHE III & 59 & & & $59.1 \%[20 / 34]$ & $p=0.067$ & \\
\hline & & & 65 & & Diltiazem & $27.3 \%[6 / 22]$ & & 38 \\
\hline \multirow[t]{4}{*}{ Seguin P, 2006 [51] } & Prospective observational & SAPS $\|$ & 47 & $10 \pm 10 \mathrm{~h}$ & DC & $100 \%[3 / 3]$ & NA & 31.2 \\
\hline & & & & & Amiodarone & $100 \%[4 / 4]$ & & \\
\hline & & & & & Digoxin & $100 \%[1 / 1]$ & & \\
\hline & & & & & No intervention & $100 \%[4 / 4]$ & & \\
\hline Sleeswijk ME, 2008 [59] & Prospective observational & APACHE ॥ & 19 & Within $24 \mathrm{~h}$ & $\mathrm{MgSO}_{4}$-amiodarone step-up scheme & $93.1 \%[27 / 29]$ & NA & 37.9 \\
\hline \multirow[t]{4}{*}{ Meierhenrich R, 2010 [53] } & Prospective observational & SAPS $\|$ & $31^{a}$ & NA & DC $(17 / 49)$ & $85.7 \%[42 / 49]^{c}$ & NA & $48^{\text {ad }}$ \\
\hline & & & $34^{b}$ & & Amiodarone (36/49) & & & $23^{\mathrm{bd}}$ \\
\hline & & & & & Digitalis (31/49) & & & \\
\hline & & & & & B-Blockers (25/49) & & & \\
\hline \multirow[t]{4}{*}{ Kanji S, 2012 [55] } & Retrospective observational & APACHE ॥ & 22.6 & Within $24 \mathrm{~h}$ & $D C^{e}$ & $26.9 \%[7 / 26]$ & NA & 32 \\
\hline & & & & & Amiodarone $^{f}$ & $87.4 \%[90 / 103]$ & & \\
\hline & & & & & Sotalol & $100 \%[2 / 2]$ & & \\
\hline & & & & & Rate control & $75 \%$ [21/28] & & \\
\hline
\end{tabular}

AF atrial fibrillation, $D C$ direct current cardioversion, $\mathrm{LOS}$ length of stay, $\mathrm{MgSO}_{4}$ magnesium sulfate, $\mathrm{NA}$ not available.

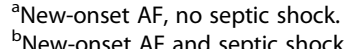

'The efficacy of each intervention was unknown because of a combination of these interventions.

${ }^{\mathrm{d}}$ Sixty-day mortality.

EEighteen of 26 had received amiodarone.

fAmiodarone alone. 
care physicians should carefully weigh the risks and benefits of anticoagulation when a critically ill patient develops new-onset AF.

As for AF prevention, we excluded two RCTs because of focusing on patients after lung resection, although they were conducted in the ICU $[60,61]$. The first study compared preemptive amiodarone and $\mathrm{MgSO}_{4}$ administration with a control, and the second study compared acebutolol and diltiazem with placebo. In the first study, both amiodarone and $\mathrm{MgSO}_{4}$ administration decreased new-onset AF and shortened ICU length of stay and hospital length of stay [60]. In the second study, although patients on acebutolol had a numerically lower incidence of new-onset AF than those on diltiazem and placebo, the difference did not reach statistical significance $(p=0.067)$ [61]. In addition, among the seven prevention studies we excluded from our systematic review, there were two RCTs for prevention of new-onset AF, one after transthoracic esophagectomy [67] and one after pulmonary resection [64]. In both studies, patients who received amiodarone had significantly less postoperative AF. In another study for patients undergoing pneumonectomy, prophylactic $\mathrm{MgSO}_{4}$ administration was also reported to reduce the incidence of SVA [68]. As for AF treatment, amiodarone and $\mathrm{MgSO}_{4}$-amiodarone step-up therapy achieved a conversion rate of more than $90 \%$ in mixed ICU patients who developed new-onset AF [59]. Although these findings suggest that amiodarone, $\mathrm{MgSO}_{4}$, or their combination might be effective to prevent or treat new-onset $\mathrm{AF}$ in specific groups in the ICU, more studies are needed to evaluate the effect of these drugs in the general ICU population.

This review has several limitations. First, we included only 12 studies and their quality of evidence was generally low. Since AF has a worse prognosis compared with other SVAs and AF in the general population and needs specific attention on anticoagulation, we strictly limited to studies that had focused on new-onset AF and excluded studies on SVA $[43,44,69]$. For example, three of four studies included in a previous systematic review on treatment for new-onset AF in non-cardiac critically ill patients were excluded in our review because these three studies also included patients with SVA [36]. We could not find any clinical trials on treatment for new-onset AF that were published after this systematic review. Second, there was a strong heterogeneity between included studies with respect to selected population and definitions of variables that had been measured, so that we could not derive conclusive statements especially on the effect of prevention and treatment of new-onset AF from this review.

\section{Conclusions}

In this systematic review, we found that new-onset $\mathrm{AF}$ occurred in $5 \%-15 \%$ of general non-cardiac critically ill patients. Patients with new-onset AF had poor outcomes compared with those without AF. Despite the high incidence of new-onset AF in the general ICU population, currently available information for AF, especially for management (prevention, treatment, and anticoagulation), is quite limited. Further research is urgently needed to improve our understanding of new-onset AF in critically ill patients.

\section{Abbreviations}

AF: Atrial fibrillation; SVA: Supraventricular arrhythmia; RCT: Randomized controlled trial; SAPS: Simplified Acute Physiology Score; APACHE: Acute Physiology and Chronic Health Evaluation; $\mathrm{MgSO}_{4}$ : Magnesium sulfate.

\section{Competing interests}

The authors declare that they have no competing interests.

\section{Authors' contributions}

TY conducted the systematic review, undertook quality assessment of selected studies, and drafted the manuscript. TF conducted the systematic review and helped to draft the manuscript. SU conceived the study, participated in its design and coordination, and revised critically the manuscript. MT made substantial contributions to conception and design and revised critically the manuscript. All authors read and approved the final manuscript.

Received: 22 January 2015 Accepted: 31 March 2015

Published online: 23 April 2015

\section{References}

1. Artucio H, Pereira M. Cardiac arrhythmias in critically ill patients: epidemiologic study. Crit Care Med. 1990;18:1383-8.

2. Trappe HJ, Brandts B, Weismueller P. Arrhythmias in the intensive care patient. Curr Opin Crit Care. 2003;9:345-55

3. Seguin $P$, Launey $Y$. Atrial fibrillation is not just an artefact in the ICU. Crit Care. 2010;14:182

4. Reinhelt P, Karth GD, Geppert A, Heinz G. Incidence and type of cardiac arrhythmias in critically ill patients: a single center experience in a medical-cardiological ICU. Intensive Care Med. 2001;27:1466-73.

5. Yoshioka I, Sakurai M, Namai A, Kawamura T. Postoperative treatment of carvedilol following low dose landiolol has preventive effect for atrial fibrillation after coronary artery bypass grafting. Thorac Cardiovasc Surg. 2009:57:464-7.

6. Daoud EG, Strickberger SA, Man KC, Goyal R, Deeb GM, Bolling SF, et al. Preoperative amiodarone as prophylaxis against atrial fibrillation after heart surgery. N Engl J Med. 1997;337:1785-91.

7. Guarnieri T, Nolan S, Gottlieb SO, Dudek A, Lowry DR. Intravenous amiodarone for the prevention of atrial fibrillation after open heart surgery: the Amiodarone Reduction in Coronary Heart (ARCH) trial. J Am Coll Cardiol. 1999;34:343-7.

8. Mitchell LB, Exner DV, Wyse DG, Connolly CJ, Prystai GD, Bayes AJ, et al. Prophylactic Oral Amiodarone for the Prevention of Arrhythmias that Begin Early After Revascularization, Valve Replacement, or Repair: PAPABEAR: a randomized controlled trial. JAMA. 2005;294:3093-100.

9. VanderLugt JT, Mattioni T, Denker S, Torchiana D, Ahern T, Wakefield LK, et al. Efficacy and safety of ibutilide fumarate for the conversion of atrial arrhythmias after cardiac surgery. Circulation. 1999;100:369-75.

10. Mathew JP, Fontes ML, Tudor IC, Ramsay J, Duke P, Mazer CD, et al. A multicenter risk index for atrial fibrillation after cardiac surgery. JAMA. 2004:291:1720-9

11. Al-Khatib SM, Hafley G, Harrington RA, Mack MJ, Ferguson TB, Peterson ED, et al. Patterns of management of atrial fibrillation complicating coronary artery bypass grafting: results from the PRoject of Ex-vivo Vein graft ENgineering via Transfection IV (PREVENT-IV) Trial. Am Heart J. 2009;158:792-8.

12. Imazio M, Brucato A, Ferrazzi P, Rovere ME, Gandino A, Cemin R, et al. Colchicine reduces postoperative atrial fibrillation: results of the Colchicine for the Prevention of the Postpericardiotomy Syndrome (COPPS) atrial fibrillation substudy. Circulation. 2011;124:2290-5.

13. Imazio M, Brucato A, Ferrazzi P, Pullara A, Adler Y, Barosi A, et al. Colchicine for prevention of postpericardiotomy syndrome and 
postoperative atrial fibrillation: the COPPS-2 randomized clinical trial. JAMA. 2014;312:1016-23.

14. Bruins $P$, Te Velthuis $H$, Yazdanbakhsh AP, Jansen PG, Van Hardevelt FW, De Beaumont EM, et al. Activation of the complement system during and after cardiopulmonary bypass surgery: postsurgery activation involves C-reactive protein and is associated with postoperative arrhythmia. Circulation. 1997;96:3542-8.

15. Halonen J, Halonen $P$, Jarvinen $O$, Taskinen $P$, Auvinen $T$, Tarkka $M$, et al. Corticosteroids for the prevention of atrial fibrillation after cardiac surgery: a randomized controlled trial. JAMA. 2007;297:1562-7.

16. Goldman L. Supraventricular tachyarrhythmias in hospitalized adults after surgery: clinical correlates in patients over 40 years of age after major noncardiac surgery. Chest. 1978;73:450-4.

17. Brathwaite $D$, Weissman $C$. The new onset of atrial arrhythmias following major noncardiothoracic surgery is associated with increased mortality. Chest. 1998;114:462-8.

18. Krowka MJ, Pairolero PC, Trastek VF, Payne WS, Bernatz PE. Cardiac dysrhythmia following pneumonectomy. Clinical correlates and prognostic significance. Chest. 1987;91:490-5.

19. Curtis JJ, Parker BM, McKenney CA, Wagner-Mann CC, Walls JT, Demmy TL, et al. Incidence and predictors of supraventricular dysrhythmias after pulmonary resection. Ann Thorac Surg. 1998;66:1766-71.

20. Dyszkiewicz W, Skrzypczak M. Atrial fibrillation after surgery of the lung: clinical analysis of risk factors. Eur J Cardiothorac Surg. 1998;13:625-8.

21. Foroulis CN, Kotoulas C, Lachanas H, Lazopoulos G, Konstantinou M, Lioulias AG. Factors associated with cardiac rhythm disturbances in the early post-pneumonectomy period: a study on 259 pneumonectomies. Eur J Cardiothorac Surg. 2003;23:384-9.

22. Von Koring J, Lepantalo M, Lindgren L, Lindfors O. Cardiac arrhythmias and myocardial ischemia after thoracotomy for lung cancer. Ann Thorac Surg. 1992:53:642-7.

23. Murthy SC, Law S, Whooley BP, Alexandrou A, Chu KM, Wong J. Atrial fibrillation after esophagectomy is a marker for postoperative morbidity and mortality. J Thorac Cardiovasc Surg. 2003;126:1162-7.

24. Rivero-Ayerza M, Scholte Op Reimer W, Lenzen M, Theuns DAMJ, Jordaens $\mathrm{L}$, Komajda $\mathrm{M}$, et al. New-onset atrial fibrillation is an independent predictor of in-hospital mortality in hospitalized heart failure patients: results of the EuroHeart Failure Survey. Eur Heart J. 2008;29:1618-24.

25. Clemo HF, Wood MA, Gilligan DM, Ellenbogen KA. Intravenous amiodarone for acute heart rate control in the critically ill patient with atrial tachyarrhythmias. Am J Cardiol. 1998;81:594-8.

26. Christian S-A, Schorr C, Ferchau L, Jarbrink ME, Parrillo JE, Gerber DR. Clinical characteristics and outcomes of septic patients with new-onset atrial fibrillation. J Crit Care. 2008;23:532-6.

27. Walkey AJ, Greiner MA, Heckbert SR, Jensen PN, Piccini JP, Sinner MF, et al. Atrial fibrillation among Medicare beneficiaries hospitalized with sepsis: incidence and risk factors. Am Heart J. 2013;165:949-55.

28. Andrews TC, Reimold SC, Berlin JA, Antman EM. Prevention of supraventricular arrhythmias after coronary artery bypass surgery. A meta-analysis of randomized control trials. Circulation. 1991;84(5):236-44.

29. Davis EM, Packard KA, Hilleman DE. Pharmacologic prophylaxis of postoperative atrial fibrillation in patients undergoing cardiac surgery: beyond beta-blockers. Pharmacotherapy. 2010;30:749. 274e-318e.

30. Koniari I, Apostolakis E, Rogkakou C, Baikoussis NG, Dougenis D. Pharmacologic prophylaxis for atrial fibrillation following cardiac surgery: a systematic review. J Cardiothorac Surg. 2010;30:121.

31. Crystal E, Garfinkle MS, Connolly SS, Ginger TT, Sleik K, Yusuf SS. Interventions for preventing post-operative atrial fibrillation in patients undergoing heart surgery. Cochrane Database Syst Rev. 2004;18:CD003611.

32. Echahidi N, Pibarot P, O'Hara G, Mathieu P. Mechanisms, prevention, and treatment of atrial fibrillation after cardiac surgery. J Am Coll Cardiol. 2008;51:793-801.

33. January CT, Wann LS, Alpert JS, Calkins H, Cigarroa JE, Cleveland Jr JC, et al 2014 AHA/ACC/HRS Guideline for the Management of Patients With Atrial Fibrillation: a report of the American College of Cardiology/American Heart Association Task Force on Practice Guidelines and the Heart Rhythm Society. J Am Coll Cardiol. 2014;64:e1-76.

34. Martinez EA, Bass EB, Zimetbaum P. Pharmacologic control of rhythm: American College of Chest Physicians guidelines for the prevention and management of postoperative atrial fibrillation after cardiac surgery. Chest. 2005; $128: 48 S-55$
35. Hunt SA, Abraham WT, Chin MH, Feldman AM, Francis GS, Ganiats TG, et al 2009 focused update incorporated into the ACC/AHA 2005 Guidelines for the Diagnosis and Management of Heart Failure in Adults: a report of the American College of Cardiology Foundation/American Heart Association Task Force on Practice Guidelines: developed in collaboration with the International Society for Heart and Lung Transplantation. Circulation. 2009;119:e391-479.

36. Kanji S, Stewart R, Fergusson DA, McIntyre L, Turgeon AF, Hébert PC. Treatment of new-onset atrial fibrillation in noncardiac intensive care unit patients: a systematic review of randomized controlled trials. Crit Care Med. 2008;36:1620-4.

37. Kuipers S, Klein Klouwenberg P, Cremer OL. Incidence, risk factors and outcomes of new-onset atrial fibrillation in patients with sepsis: a systematic review. Crit Care. 2014;18:688

38. Bogun F, Anh D, Kalahasty G, Wissner E, Bou Serhal C, Bazzi R, et al. Misdiagnosis of atrial fibrillation and its clinical consequences. Am J Med. 2004;117:636-42.

39. Buttà C, Tuttolomondo A, Di Raimondo D, Milio G, Miceli S, Attanzio MT, et al. Supraventricular tachycardias: proposal of a diagnostic algorithm for the narrow complex tachycardias. J Cardiol. 2013;61:247-55.

40. Saoudi N, Cosío F, Waldo A, Chen SA, lesaka Y, Lesh M, et al. A classification of atrial flutter and regular atrial tachycardia according to electrophysiological mechanisms and anatomical bases; a statement from a Joint Expert Group from The Working Group of Arrhythmias of the European Society of Cardiology and the North American Society of Pacing and Electrophysiology. Eur Heart J. 2001;22:1162-82.

41. Mayr A, Ritsch N, Knotzer H, Dünser M, Schobersberger W, Ulmer H, et al. Effectiveness of direct-current cardioversion for treatment of supraventricular tachyarrhythmias, in particular atrial fibrillation, in surgical intensive care patients. Crit Care Med. 2003;31:401-5.

42. Weigner MJ, Caulfield TA, Danias PG, Silverman DI, Manning WJ. Risk for clinical thromboembolism associated with conversion to sinus rhythm in patients with atrial fibrillation lasting less than 48 hours. Ann Intern Med. 1997;126:615-20.

43. Clark DM, Plumb VJ, Epstein AE, Kay GN. Hemodynamic effects of an irregular sequence of ventricular cycle lengths during atrial fibrillation. J Am Coll Cardiol. 1997;30:1039-45.

44. Gage BF, Waterman AD, Shannon W, Boechler M, Rich MW, Radford MJ. Validation of clinical classification schemes for predicting stroke: results from the National Registry of Atrial Fibrillation. JAMA. 2001;285:2864-70.

45. Olesen JB, Lip GY, Hansen ML, Hansen PR, Tolstrup JS, Lindhardsen J, et al. Validation of risk stratification schemes for predicting stroke and thromboembolism in patients with atrial fibrillation: nationwide cohort study. BMJ. 2011;342:d124.

46. Mehta D, Baruch L. Thromboembolism following cardioversion of "common" atrial flutter. Risk factors and limitations of transesophageal echocardiography. Chest. 1996;110:1001-3.

47. Irani WN, Grayburn PA, Afridi I. Prevalence of thrombus, spontaneous echo contrast, and atrial stunning in patients undergoing cardioversion of atrial flutter. A prospective study using transesophageal echocardiography. Circulation. 1997:95:962-6.

48. Balshem H, Helfand M, Schunemann HJ, Oxman AD, Kunz R, Brozek J, et al. GRADE guidelines: 3. Rating the quality of evidence. J Clin Epidemiol. 2011;64:401-6.

49. Bender JS. Supraventricular tachyarrhythmias in the surgical intensive care unit: an under-recognized event. Am Surg. 1996;62:73-5.

50. Seguin $P$, Signouret $T$, Laviolle B, Branger B, Mallédant $Y$. Incidence and risk factors of atrial fibrillation in a surgical intensive care unit. Crit Care Med. 2004;32:722-6.

51. Seguin $P$, Laviolle $B$, Maurice $A$, Leclerca $C$, Mallédant $Y$. Atrial fibrillation in trauma patients requiring intensive care. Intensive Care Med. 2006;32:398-404.

52. Arora S, Lang I, Nayyar V, Stachowski E, Ross DL. Atrial fibrillation in a tertiary care multidisciplinary intensive care unit-incidence and risk factors. Anaesth Intensive Care. 2007;35:707-13.

53. Meierhenrich R, Steinhilber E, Eggermann C, Weiss M, Voglic S, Bögelein D, et al. Incidence and prognostic impact of new-onset atrial fibrillation in patients with septic shock: a prospective observational study. Crit Care. 2010;14:R108.

54. Walkey AJ, Wiener RS, Ghobrial JM, Curtis LH, Benjamin EJ. Incident stroke and mortality associated with new-onset atrial fibrillation in patients hospitalized with severe sepsis. JAMA. 2011;306:2248-54. 
55. Kanji S, Williamson DR, Yaghchi BM, Albert M, Mclntyre L, Canadian Critical Care Trials Group. Epidemiology and management of atrial fibrillation in medical and noncardiac surgical adult intensive care unit patients. J Crit Care. 2012;27:326. e1-8.

56. Tongyaoo S, Permpikul C, Haemin R, Epichath N. Predicting factors, incidence and prognosis of cardiac arrhythmia in medical, non-acute coronary syndrome, critically ill patients. J Med Assoc Thai. 2013;96 Supp 2:238-45.

57. Makrygiannis SS, Margariti A, Rizikou D, Lampakis M, Vangelis S, Ampartzidou OS, et al. Incidence and predictors of new-onset atrial fibrillation in noncardiac intensive care unit patients. J Crit Care. 2014;29:697. e1-5.

58. Balser JR, Martinez EA, Winters BD, Perdue PW, Clarke AW, Huang W, et al. Beta-adrenergic blockade accelerates conversion of postoperative supraventricular tachyarrhythmias. Anesthesiology. 1998;89:1052-9.

59. Sleeswijk ME, Tulleken JE, Van Noord T, Meertens JH, Ligtenberg JJ, Zijlstra $J G$. Efficacy of magnesium-amiodarone step-up scheme in critically ill patients with new-onset atrial fibrillation: a prospective observational study. J Intensive Care Med. 2008;23:61-6.

60. Khalil MA, Al-Agaty AE, Ali WG, Abdel Azeem MS. A comparative study between amiodarone and magnesium sulfate as antiarrhythmic agents for prophylaxis against atrial fibrillation following lobectomy. J Anesth. 2013;27:56-61.

61. Ciszewski P, Tyczka J, Nadolski J, Roszak M, Dyszkiewicz W. Comparative efficacy and usefulness of acebutolol and diltiazem for the prevention of atrial fibrillation during perioperative time in patients undergoing pulmonary resection. Thorac Cardiovasc Surg. 2013;61:365-72.

62. Le Gall JR, Lemeshow S, Saulnier F. A new Simplified Acute Physiology Score (SAPS II) based on a European/North American multicenter study. JAMA. 1993;270:2957-63.

63. Knaus WA, Draper EA, Wagner DP, Zimmerman JE. APACHE II: a severity of disease classification system. Crit Care Med. 1985;13:818-29.

64. Tisdale JE, Wroblewski HA, Wall DS, Rieger KM, Hammoud ZT, Young JV, et al. A randomized trial evaluating amiodarone for prevention of atrial fibrillation after pulmonary resection. Ann Thorac Surg. 2009;88:886-95.

65. Sprung $C L$, Annane D, Keh D, Moreno R, Singer M, Freivogel $K$, et al. Hydrocortisone therapy for patients with septic shock. N Engl J Med. 2008;358:111-24.

66. Champion S, Lefort Y, Gaüzère BA, Drouet D, Bouchet BJ, Bossard G, et al. CHADS2 and CHA2DS2-VASc scores can predict thromboembolic events after supraventricular arrhythmia in the critically ill patients. J Crit Care. 2014:29:854-8

67. Tisdale JE, Wroblewski HA, Wall DS, Rieger KM, Hammoud ZT, Young JV, et al. A randomized, controlled study of amiodarone for prevention of atrial fibrillation after transthoracic esophagectomy. J Thorac Cardiovasc Surg. 2010;140:45-51.

68. Saran T, Perkins GD, Javed MA, Annam V, Leong L, Gao F, et al. Does the prophylactic administration of magnesium sulphate to patients undergoing thoracotomy prevent postoperative supraventricular arrhythmias? A randomized controlled trial. Br J Anaesth. 2011;106:785-91.

69. Nathanson MH, Gajraj NM. The peri-operative management of atrial fibrillation. Anaesthesia. 1998;53:665-76.

\section{Submit your next manuscript to BioMed Central and take full advantage of:}

- Convenient online submission

- Thorough peer review

- No space constraints or color figure charges

- Immediate publication on acceptance

- Inclusion in PubMed, CAS, Scopus and Google Scholar

- Research which is freely available for redistribution 